\title{
MORFOGÊNESE E ESTRUTURA DO CAPIM-BRAQUIÁRIA EM SISTEMA DE INTEGRAÇÃO AGRICULTURA E PECUÁRIA
}

\author{
Janaina Azevedo Martuscello ${ }^{1}$, Philipe Lima Amorim² ${ }^{*}$, Daniel de Noronha Figueiredo Vieira da Cunha ${ }^{1}$, \\ Paulo Sérgio Ferreira ${ }^{3}$, Luana Santos Ribeiro ${ }^{4}$, Madson Williame Melo Souza ${ }^{3}$
}

\author{
${ }^{1}$ Universidade Federal de São João Del-Rei, Campus CTAN, São João Del-Rei, Minas Gerais \\ 2 Universidade Federal de Alagoas, Centro de Ciências Agrárias, Rio Largo, Alagoas \\ ${ }^{3}$ Universidade Federal Rural de Pernambuco, Recife, Pernambuco \\ ${ }^{4}$ Universidade Federal da Bahia, Salvador, Bahia \\ *Autor para correspondência: Philipe Lima Amorim, philipe.amorim@ceca.ufal.br
}

\begin{abstract}
RESUMO: Objetivou-se avaliar a morfogênese e estrutura do capim-braquiária em sistemas de integração agricultura e pecuária. Foram avaliados três tratamentos: capim-braquiária em monocultivo, consorciado com milho e com sorgo, num delineamento experimental de blocos completos casualizados, com três repetições. Houve diferenças significativas para características morfogênicas, sendo o capim-braquiária consorciado com milho aquele que apresentou maiores valores médios no período pré-colheita. Independente do tratamento houve redução do número de perfilhos basilares na pré-colheita, elevando-se novamente após a retirada desta. O capim-braquiária quando consorciado com sorgo, apresentou maiores valores para produção de massa seca total e lâminas foliares no período pré-colheita. A massa de forragem, características morfogênicas e estruturais do capim-braquiária são influenciadas pelo sistema de cultivo na integração agricultura e pecuária somente no período pré-colheita. 0 consórcio de capim-braquiária com milho ou sorgo, não modifica sua composição química, nem prejudica seu estabelecimento e favorece aumento na produção de massa seca após retirada das culturas agrícolas.
\end{abstract}

PALAVRAS-CHAVE: estrutura, massa seca, milho, sorgo, Urochloa decumbens.

\section{MORPHOGENESIS AND STRUCTURE OF SIGNAL GRASS IN CROP LIVESTOCK INTEGRATION SYSTEM}

ABSTRACT: This study aimed to evaluate the morphogenesis and structure of signal grass in crop-livestock integration systems. Three treatments were evaluated: signal grass monoculture, intercropped with maize and sorghum, in a randomized complete block design with three replications. There were significant differences in morphogenesis and the signal grass intercropped with corn one that showed higher average values in the pre-harvest period. Regardless of treatment, a reduction in the number of basal tillers in the pre-harvest, rising again after this withdrawal. The signal grass when intercropped with sorghum, showed higher values for total dry matter production and leaf blades in the pre-harvest period. The forage mass, morphogenetic and structural characteristics of signal grass are influenced by the cropping system in crop-livestock integration only in the pre-harvest period. The signal grass consortium with corn or sorghum, does not change its chemical composition or adversely affect their establishment and favors increase in dry matter production after withdrawal of agricultural crops.

KEYWORDS: corn, dry mass, sorghum, structure, Urochloa decumbens

\section{INTRODUÇÃO}

A integração entre agricultura e pecuária é um sistema planejado que envolve (temporal e espacialmente) interações em diferentes escalas com exploração de animais e cultura agrícola na mesma área (Moraes et al., 2013). Esse sistema vem sendo utilizado há vários anos no Brasil Central, entretanto, essa tecnologia é ainda pouco utilizada no nordeste brasileiro, com poucos relatos na literatura. 
A integração entre agricultura e pecuária representa um avanço na sustentabilidade da agropecuária, uma vez que permite simultaneamente a agregação de valores, uso intensivo da propriedade, redução e, ou, amortização dos custos de produção e aumento na produtividade, acrescentando-se 0 respeito ao meio ambiente. Assim, é um sistema que pode ser utilizado também na região nordeste para estabelecimento ou recuperação de áreas de pastagem.

No nordeste brasileiro, essa alternativa pode ser viável e importante, uma vez que a baixa disponibilidade e má distribuição das chuvas fazem com que o sistema de produção animal seja ainda mais dependente de insumos externos.

O milho para silagem é uma cultura bastante adotada na região do Agreste, porém, sua produtividade é baixa devido a fatores ambientais e de manejo, havendo, neste caso, necessidade de avaliação de outras culturas para que a produtividade possa ser incrementada. Já o sorgo é uma alternativa para esse tipo de região, uma vez que apresenta certa resistência à alta temperatura e déficit hídrico, mesmo que por vezes apresente silagem de qualidade inferior, quando comparada a de milho (Nascimento et al., 2008).

A combinação correta entre planta forrageira e a cultura é essencial para o sucesso da integração agricultura e pecuária, assim avaliações são também necessárias quanto a forrageira a ser cultivada nesse sistema. Assim, algumas forrageiras cultivadas vêm sendo adotadas no nordeste com relativo sucesso, como é o caso do gênero Urochloa, com destaque para a Urochloa decumbens cv. Basilisk. Entretanto, grande parte destas pastagens encontra-se degradadas e, ou, em estádio de degradação, e neste caso, a avaliação dessa forrageira em sistema de integração com milho ou sorgo, pode trazer resultados promissores que culminariam no aumento da produção pecuária no agreste brasileiro.

Diante do exposto, objetivou-se avaliar as características de produção, morfogênicas e estruturais e composição química do capim-braquiária em sistema consórcio com milho ou sorgo.

\section{MATERIAL E MÉTODOS}

O trabalho foi conduzido na Universidade Federal de Alagoas, Campus Arapiraca, de julho de
2009 a março de 2010 em área experimental com as seguintes coordenadas: latitude $9^{\circ} 45^{\prime} 6^{\prime \prime}$ Sul e longitude $36^{\circ} 39^{\prime} 37^{\prime \prime}$ oeste. $O$ município de Arapiraca situa-se na região do agreste sub-úmido, onde o clima é do tipo As', segundo a classificação climática descrita por Köppen, com estação seca no verão e chuvas de outono a inverno.

O solo da área experimental foi colhido $e$ avaliado quanto às características químicas. As amostras de solo foram coletadas na camada de 0 a $20 \mathrm{~cm}$ e enviadas para análise em laboratório. A classificação de solo é tipo latossolo vermelho amarelo (Embrapa, 2013). Os resultados da análise revelaram os seguintes valores: $\mathrm{pH}\left(\mathrm{H}_{2} \mathrm{O}\right) 5,4 ; \mathrm{Ca}$ $\left(\mathrm{cmol}_{c} / \mathrm{dm}^{3}\right)$ 4,7; $\mathrm{Mg}\left(\mathrm{cmol}_{\mathrm{c}} / \mathrm{dm}^{3}\right)$ 2,2; $\mathrm{Al}\left(\mathrm{cmol}_{\mathrm{c}} /\right.$ $\mathrm{dm}^{3}$ ) 0,0; $\mathrm{H}+\mathrm{Al}\left(\mathrm{cmol}_{\mathrm{c}} / \mathrm{dm}^{3}\right)$ 4,0; P $\left(\mathrm{mg} / \mathrm{dm}^{3}\right)$ 68; K $\left(\mathrm{mg} / \mathrm{dm}^{3}\right)$ 142; SB $\left(\mathrm{cmol}_{\mathrm{c}} / \mathrm{dm}^{3}\right)$ 7,23; CTC $\left(\mathrm{cmol}_{\mathrm{c}} /\right.$ $\mathrm{dm}^{3}$ ) 11,23; V (\%) 64,4; M.O (g/kg) 11,7. Os dados meteorológicos do período experimental são apresentados na Figura 1.

Figura 1. Precipitação pluviométrica $(\mathrm{mm})$ e temperaturas $\left({ }^{\circ} \mathrm{C}\right)$ máxima $(A)$, média $(B)$ e mínima (C) do município de Arapiraca - Alagoas/Brasil, durante o período experimental.

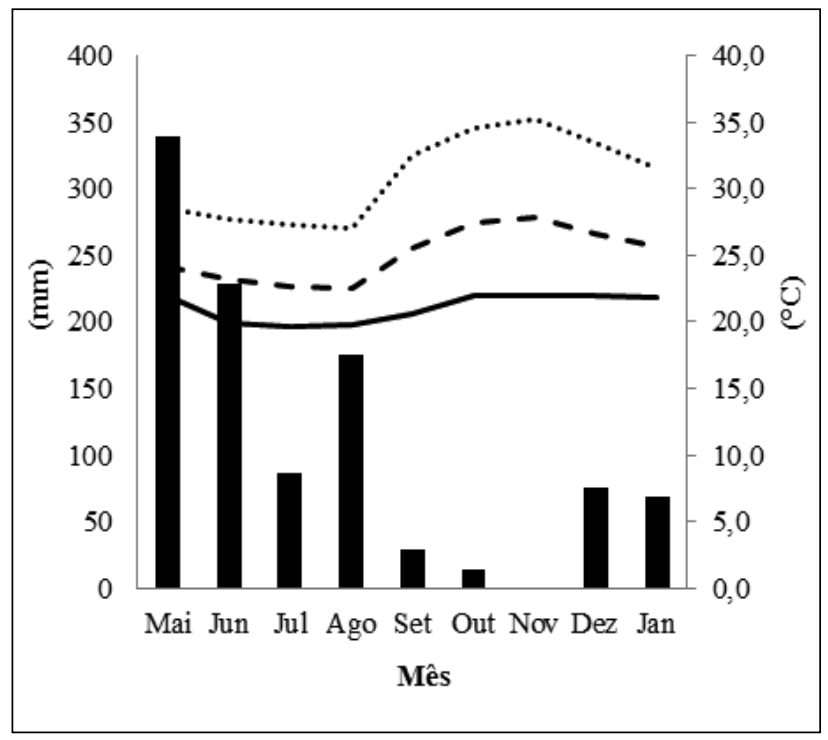

Foram avaliados três tratamentos, capimbraquiária cv. Basilisk (Urochloa decumbens) em monocultivo, sorgo (Sorghum bicolor) consorciado com capim-braquiária e milho (Zea mays) consorciado com capim-braquiária num delineamento experimental de blocos completos casualizados com três repetições. 
As plantas foram semeadas em parcelas de $25 \mathrm{~m}^{2}$. 0 milho e o sorgo foram semeados com espaçamento de $0,8 \mathrm{~m}$ entre linhas e 0,1 $\mathrm{m}$ na linha, respectivamente. Nos tratamentos consorciados, 0 capim-braquiária foi semeado nas entre linhas das culturas com espaçamento de 0,4 m. Em monocultivo, o capim-braquiária foi semeado com espaçamento entre linhas de 0,4 m.

A adubação para o tratamento consorciado com milho foi de $130 \mathrm{~kg} / \mathrm{ha}$ de nitrogênio, na forma de ureia, aplicados em duas doses (22/06/2009 e 08/07/2009) e $80 \mathrm{~kg} / \mathrm{ha}$ de $\mathrm{K}_{2} \mathrm{O}$, na forma de cloreto de potássio, também aplicados em duas doses concomitantemente com a adubação nitrogenada. Para o tratamento consorciado com sorgo as doses de $\mathrm{Ne}$ $\mathrm{K}_{2} \mathrm{O}$ corresponderam respectivamente a 100 e $60 \mathrm{~kg} /$ ha, também parcelados em duas aplicações, como no tratamento consorciado com milho. Para monocultivo de capim-braquiária foram aplicados $50 \mathrm{~kg} / \mathrm{ha}$ de $\mathrm{Ne}$ $30 \mathrm{~kg} / \mathrm{ha}$ de $\mathrm{K}_{2} \mathrm{O}$ em única dose no dia 22/06/2009.

$\mathrm{Na}$ avaliação da altura das plantas foram selecionadas três plantas por parcela. A altura das plantas selecionadas de capim-braquiária foram medidas a cada dois dias. Os dados obtidos com as medições foram utilizados para obtenção das curvas de crescimento das plantas. As curvas de crescimento foram obtidas, por parcela, por meio de ajuste do modelo matemático proposto por Lopez et al., (2000) (Equação 1).

$$
y=\frac{a \cdot k^{c}+b \cdot x^{c}}{k^{c}+x^{c}}
$$

\section{Em que:}

$a=$ tamanho inicial,

$b=$ tamanho final,

$k=$ tempo para atingir $50 \%$ do valor final do fenômeno de crescimento,

$c=$ parâmetro relacionado ao formato sigmóide da curva, sem significado biológico e

$x=$ tempo.

Em cada parcela, o tamanho final das plantas foi obtido a partir do valor do parâmetro $b$ do modelo ajustado. Da mesma forma, o valor do parâmetro $k$ do modelo foi computado como 0 número de dias para que as plantas atingissem $50 \%$ do seu tamanho final.
$\mathrm{Na}$ avaliação das características morfogênicas e estruturais foram selecionados, em cada unidade experimental, dois perfilhos de capim-braquiária os quais foram devidamente identificados com arame colorido e avaliados duas vezes por semana. Para as medições utilizou-se régua, graduada em centímetros. As avaliações de morfogênese foram divididas em pré-colheita (antes da colheita do milho ou sorgo) e pós-colheita (após colheita do milho ou sorgo).

As avaliações foram realizadas com registro de aparecimento do ápice foliar, dia da exposição da lígula, comprimento final das folhas expandidas e em expansão, senescência foliar (comprimento total da lâmina menos o comprimento da lâmina ainda verde) e número de folhas vivas por perfilho. Em seguida, foram classificadas em características estruturais (TAIC - cm.dia ${ }^{-1}$, NFV - folhas.perfilho-1, CFL (comprimento final da lâmina) $-\mathrm{cm}$ perfilho-1) e morfogênicas: taxa de alongamento foliar (TAIF $\mathrm{cm}$. dia $^{-1}$ ) expressa em $\mathrm{cm} / \mathrm{dia}$; taxa de aparecimento foliar (TApF cm.dia ${ }^{-1}$ ); filocrono (número de dias para o aparecimento de duas folhas consecutivas);; taxa de senescência foliar (TSeF - cm/dia) e duração de vida das folhas (DVF - dias).

As plantas nas parcelas foram colhidas quando milho ou sorgo apresentaram teor de massa seca entre 25 e $35 \%$. Todas as plantas de milho ou sorgo, excetuando-se aquelas da bordadura, foram colhidas e pesadas para estimativa de produção de massa fresca.

Para estimativa da produção de massa seca, as plantas de milho ou sorgo foram sub-amostradas e secas em estufa de ventilação forçada de ar a 55 ${ }^{\circ} \mathrm{C}$. Após a primeira colheita, as plantas de capimbraquiária passaram por uma segunda colheita após 60 dias de rebrotação.

Para avaliação da produção de massa seca das colheitas, um quadrado $1 \mathrm{~m}^{2}$ foi alocado aleatoriamente na parcela quando as plantas atingiam as alturas em torno de $50 \mathrm{~cm}$. Imediatamente após colheita, toda forragem cortada no quadrado de amostragem foi pesada para obtenção da produção de massa fresca total (MFT). Após este procedimento, as plantas foram separadas em lâmina foliares, colmo + bainha (pseudocolmo) e forragem morta, em seguida os componentes morfológicos foram secos em estufa de ventilação forçada a $55{ }^{\circ} \mathrm{C}$ até peso constante e 
posteriormente pesado para estimativa da produção de massa seca total (MST), massa seca de lâmina foliar (MSLF), massa seca de colmo (MSC) e massa seca de forragem morta (MSFM).

Amostras secas em estufa de capim-braquiária, foram moídas em moinho de facas (tipo Willey) em peneiras com malha de $1 \mathrm{~mm}$ e posteriormente levadas a estufa com circulação forçada de ar a $105^{\circ} \mathrm{C}$, por $16 \mathrm{~h}$. Após secagem definitiva, as amostras foram pesadas, sendo estimados posteriormente os teores de matéria seca, matéria mineral, fibra em detergente neutro e ácido, segundo métodos compilados e descritos por Detmann et al. (2013).

Para avaliação dos padrões demográficos de perfilhamento e suas respectivas taxas de aparecimento, mortalidade e sobrevivência de perfilhos basilares foram selecionadas, aleatoriamente, duas touceiras em cada unidade experimental e identificadas com anéis coloridos. 0 número de perfilhos inicial foi contado e marcado e a cada 21 dias foram realizadas novas marcações e contagens do número de perfilhos de cada geração existente (cores diferentes). Os perfilhos foram avaliados em oito gerações. As taxas de aparecimento, mortalidade e sobrevivência de perfilhos basilares foram calculadas com dados provenientes de duas touceiras por unidade experimental, de acordo com as seguintes fórmulas: Taxa de aparecimento $=\left[n^{0}\right.$ de perfilhos novos (última geração marcada)] x 100/ $n^{0}$ de perfilhos totais existentes (gerações marcados anteriores); Taxa de mortalidade $=$ (perfilhos marcados anteriores - perfilhos sobreviventes) $\times 100 / n^{0}$ total de perfilhos na marcação anterior; Taxa de sobrevivência = $\left(n^{0}\right.$ de perfilhos da marcação anterior vivos na marcação atual $\times 100) / n^{0}$ de perfilhos vivos na marcação anterior. As gerações 1, 2 e 3 foram classificadas com gerações de pré-colheita (antes da colheita do milho ou sorgo) e as demais como pós-colheita (após colheita do milho e sorgo).

Os dados obtidos foram submetidos a analise de variância e as médias comparadas pelo teste de Tukey a $5 \%$ de probabilidade para o erro tipo I. Para tal, foi utilizado o procedimento GLM do SAS 9.0, excetuando-se as características tamanho final das plantas e número de dias necessários para chegar a $50 \%$ do tamanho final, onde utilizou-se procedimento NLIN do SAS 9.0 (SAS institute, 2009). Os dados de dinâmica de perfilhamento foram avaliados por estatística descritiva utilizando-se 0 erro padrão da média como medida de dispersão.

\section{RESULTADOS E DISCUSSÃO}

Não houve efeito $(P>0,05)$ do sistema de cultivo sobre a altura final das plantas capim-braquiária (Tabela 1). Embora o sistema de cultivo não tenha influenciado $(P>0,05)$ a altura final das plantas de capim-braquiária, o cultivo em consórcio resultou na redução $(P<0,05)$ do número de dias para que as plantas de capimbraquiária atingissem $50 \%$ da altura final (Tabela 1).

Tabela 1. Altura final e número de dias para atingir $50 \%$ da altura final em plantas de Urochloa decumbens cultivadas em monocultivo ou consorciado com milho ou sorgo

\begin{tabular}{lcccc}
\hline \multirow{2}{*}{ Variáveis } & \multicolumn{3}{c}{ Braquiária } & \multirow{2}{*}{ CV (\%) } \\
\cline { 2 - 4 } & Monocultivo & Milho & Sorgo & \\
\hline Altura final da Planta $(\mathrm{cm})$ & 114,53 & 101,82 & 107,28 & 7,58 \\
N50 (dias) & $45,17 \mathrm{a}$ & $37,16 \mathrm{~b}$ & $41,86 \mathrm{ab}$ & 6,58 \\
\hline
\end{tabular}

N50 = Número de dias para a planta atingir $50 \%$ de seu tamanho final. CV = Coeficiente de variação.

Médias na mesma linha, seguidas por letras diferentes diferem ao nível de $5 \%$ de probabilidade pelo teste de Tukey.

Variações na disponibilidade dos fatores abióticos e manejo as plantas são responsáveis por modificações na morfogênese das plantas, acarretando, desse modo, em mudanças na estrutura e por fim na massa de forragem (Chapman e Lemaire, 1993). No caso de forrageiras consorciadas em sistemas de integração entre agricultura e pecuária a competição por fatores abióticos de crescimento, sobretudo por luz, é maior, uma vez que, em grande parte dos casos as culturas agrícolas foram melhoradas geneticamente pra serem mais responsivas a práticas de manejo, tornando-as exigentes. 
No período pré-colheita (Tabela 2), observou-se efeito do sistema de cultivo $(P<0,05)$ sobre a TAIC, DVF e TSeF. No período pós-colheita, somente o filocrono do capim-braquiária foi influenciado pelos tratamentos $(\mathrm{P}<0,05)$ (Tabela 2). 0 capim-braquiária, no período précolheita, em monocultivo, apresentou menores valores para taxa de alongamento de colmo, sendo os maiores valores observados quando cultivada em consórcio com milho. Os sistemas de cultivo do capim-braquiária em monocultivo e com sorgo apresentaram os maiores valores $(P<0,05)$ para duração de vida da folha quando comparados ao cultivo com milho. Já, quando cultivado com milho, o capim-braquiária apresentou os maiores valores $(P<0,05)$ médios para TSeF.

Tabela 2. Taxa de aparecimento de folhas, taxa de alongamento de folhas e colmos, filocrono, duração de vida da folha e taxa de senescência foliar do capim-braquiária consorciado ou em monocultivo

\begin{tabular}{|c|c|c|c|c|}
\hline \multirow{2}{*}{ Variáveis } & \multicolumn{3}{|c|}{ Braquiária } & \multirow{2}{*}{ CV $(\%)$} \\
\hline & Monocultivo & Milho & Sorgo & \\
\hline \multicolumn{5}{|c|}{ Pré-colheita } \\
\hline TApF(folhas /dia) & 0,17 & 0,13 & 0,14 & 11,54 \\
\hline TAIF (cm/dia) & 2,05 & 1,97 & 2,12 & 10,64 \\
\hline TAIC (cm/dia) & $0,87 b$ & $1,13 a$ & $1,08 a b$ & 17,93 \\
\hline Filocrono (dias) & 6,06 & 7,58 & 7,25 & 11,28 \\
\hline DVF (dias) & $34,13 a$ & $23,33 b$ & $32,40^{a}$ & 29,11 \\
\hline TSeF (cm/dia) & $1,14 b$ & $2,95 a$ & $1,65 b$ & 41,38 \\
\hline \multicolumn{5}{|c|}{ Pós-colheita } \\
\hline TApF (folhas/dia) & 0,06 & 0,19 & 0,15 & 10,84 \\
\hline TAIF (cm/dia) & 0,41 & 0,47 & 0,65 & 16,52 \\
\hline TAIC (cm/dia) & 0,16 & 0,12 & 0,16 & 39,41 \\
\hline Filocrono (dias) & $11,71 b$ & $18,90 a$ & $14,70 \mathrm{~b}$ & 22,17 \\
\hline DVF (dias) & 90,05 & 72,29 & 89,13 & 21,96 \\
\hline TSeF (cm/dia) & 0,44 & 0,34 & 0,43 & 65,15 \\
\hline
\end{tabular}

Taxa de aparecimento foliar (TApF); taxa de alongamento foliar (TAIF); taxa de alongamento do pseudocolmo (TAIPC); duração de vida da folha (DVF); taxa de senescência foliar (TSeF) e número de folhas vivas (NFV); CV= coeficiente de variação. Médias seguidas da mesma letra na linha, dentro do corte, não diferem entre si pelo teste Tukey a $5 \%$ de probabilidade.

Mesmo em desvantagem, principalmente quanto à captação por luz, o capim-braquiária consorciado pôde apresentar crescimento semelhante ao monocultivo, devido a sua plasticidade fenotípica, modificando sua morfogênese e estrutura, a fim de manter certa taxa de crescimento. Tal afirmativa pode ser corroborada observando os valores médios para TAIC, DVF e TSeF (Tabela 2). Com objetivo de aumentar a captação de luz, inevitavelmente 0 capimbraquiária cria estrutura desfavorável, interferindo, desse modo, na sua própria rebrotação. Com colheita do capim-braquiária há uma consequente diminuição da competição por luz, nutrientes e água, havendo reestabelecimento não só de sua área foliar, através do aumento das taxas de aparecimento (filocrono) e alongamento de lâminas (Tabela 2), mas também da ocupação de espaços vazios no solo pelo perfilhamento.
Com crescimento das culturas agrícolas, pode-se observar que houve redução do número de perfilhos nas gerações dois e três, em comparação a geração um (Tabela 3). Com a colheita do milho e sorgo, maiores valores de perfilhos basilares por geração foram observados no capim-braquiária, 0 que é indicativo de reestabelecimento do dossel, principalmente pela diminuição da competição por recursos abióticos, com destaque para luminosidade. Isso porque a maior intensidade de radiação e aumento relação dos comprimentos de onda vermelho/vermelho extremo induzem 0 perfilhamento (Deregibus et al., 1983). Brambrilla et al. (2009), avaliando o perfilhamento de $U$. ruziziensis, em consócio com milho, observaram diferença significativa entre tratamentos, com milho consorciado com essa planta. 
Tabela 3. Número de perfilhos basilares por planta, por geração, em capim-braquiária consorciado ou em monocultivo e seus respectivos erros padrões da média

\begin{tabular}{cccc}
\hline \multirow{2}{*}{ Gerações } & \multicolumn{3}{c}{ Braquiária } \\
\cline { 2 - 4 } & Monocultivo & Milho & Sorgo \\
\hline 1 & $12,85( \pm 3,04)$ & $10,85 \pm 1,81$ & $10,60 \pm 2,28$ \\
2 & $4,02( \pm 1,15)$ & $5,64 \pm 1,77$ & $0,52 \pm 0,20$ \\
3 & $1,58( \pm 0,87)$ & $2,97 \pm 0,73$ & $1,16 \pm 0,06$ \\
$4^{*}$ & $14,43 \pm 0,83$ & $14,13 \pm 0,71$ & $9,09 \pm 0,13$ \\
5 & $6,62 \pm 0,36$ & $12,83 \pm 0,28$ & $16,12 \pm 0,04$ \\
6 & $1,83 \pm 0,16$ & $1,22 \pm 0,20$ & $3,16 \pm 3,33$ \\
7 & $1,08 \pm 0,08$ & $2,33 \pm 0$ & $5,58 \pm 0,75$ \\
8 & $3,83 \pm 0$ & $4,83 \pm 0$ & $10 \pm 0$ \\
\hline
\end{tabular}

*Pós-colheita do milho e sorgo.

Não foram observadas diferenças significativas $(P>0,05)$ para as taxas de aparecimento, sobrevivência e mortalidade de perfilhos no período de pré-colheita (Tabela 4). Já no período pós-colheita, maiores taxas de aparecimento, sobrevivência e menores taxas de mortalidade de perfilhos $(P<0,05)$ para o capimbraquiária puderam ser observados quando cultivado com milho.

Tabela 4. Taxas de aparecimento, mortalidade e sobrevivência de perfilhos em capim-braquiária consorciado ou em monocultivo

\begin{tabular}{ccccc}
\hline \multirow{2}{*}{ Variáveis } & \multicolumn{3}{c}{ Braquiária } & CV (\%) \\
\cline { 2 - 4 } & Monocultivo & Milho & Sorgo & 33,4 \\
Taxa de Aparecimento & 49,92 & Pré-colheita & 39,98 & 31,5 \\
Taxa de Mortalidade & 16,04 & 51,85 & 17,34 & 5,8 \\
Taxa de Sobrevivência & 83,95 & 10,89 & 82,47 & 33,7 \\
& & 87,07 & $20,15^{\mathrm{a}}$ & 43,9 \\
Taxa de Aparecimento & $8,48 \mathrm{~b}$ & Pós-colheita & $1,97 \mathrm{~b}$ & 3,6 \\
Taxa de Mortalidade & $11,56 \mathrm{a}$ & $7,45 \mathrm{~b}$ & $97,92^{\mathrm{a}}$ & \\
Taxa de Sobrevivência & $89,06 \mathrm{~b}$ & $9,73 \mathrm{a}$ & $92,26 \mathrm{ab}$ &
\end{tabular}

$\overline{\mathrm{CV}}=$ Coeficiente de variação. Médias na mesma linha, seguidas por letras diferentes diferem ao nível de $5 \%$ de probabilidade pelo teste de Tukey.

No estabelecimento do sistema de consórcio, a competição ainda é baixa, fazendo com que o capimbraquiária ocupe os espaços vazios no solo através da emissão de novos perfilhos, sobretudo basilares (Tabela 3). Por apresentarem crescimento acelerado, milho e sorgo aumentam a competição por luz, inibindo consequentemente o perfilhamento da forrageira, pela modificação na quantidade e qualidade da luz que chega às gemas basilares. 0 perfilhamento geralmente é um indicador de vigor e persistência de plantas forrageiras e pode ser afetado por uma série de fatores ambientais. A demografia de perfilhos varia substancialmente entre gramíneas e geralmente começa a declinar antes do início da emissão das inflorescências ou em situação de auto-sombreamento. Esse declínio decorre de elevada taxa de mortalidade de perfilhos, até mesmo antes de completaremseu desenvolvimento(Nabinger\&Medeiros, 1995), fato esse que pode ser observado até a geração que antecede a colheita das culturas agrícolas (final da $3^{a}$ geração). Situação semelhante ocorre para pastos diferidos, Sousa et al. (2012) em estudo sobre dinâmica do perfilhamento do capim-piatã diferido, observaram que a medida que o período de diferimento avançava e a estrutura se tornava desfavorável, ocorreu diminuições nas taxas de aparecimento de perfilhos, enquanto as taxas de mortalidade se elevavam. Os autores atribuíram o fato, a modificação do ambiente, sobretudo, luminoso e condições climáticas desfavoráveis, que favoreceram 
diminuição da sobrevivência, principalmente de perfilhos mais jovens.

Em sistemas de integração agricultura e pecuária há tendência de redução da produção de forragem quando essas estão em consórcio em comparação ao monocultivo (Leonel et al., 2009; Portes et al., 2000). Neste caso, ocorreu devido à redução no aparecimento de perfilhos, que apresenta alta correlação com a produção de forragem. De fato, o reduzido número de perfilhos surgidos, mesmo estes sendo de maior tamanho, no capim-braquiária consorciado com milho comparativamente aos demais tratamentos (Tabela 3), refletiu em menor produção de biomassa, indicando que a competição por recursos tróficos foi intensa com essa cultura. Características estruturais do milho tais como, ângulo de inserção de lâminas foliares, altura ou até mesmo densidade de plantas na área provavelmente contribuíram com maior sombreamento do capim-braquiária. No entanto, após a colheita das culturas agrícolas, conforme discutido anteriormente, a adubação aplicada na cultura do milho, que foi maior que no sorgo, pode ter produzido maior resíduo, proporcionando ao capim-braquiária recursos suficientes para apresentar maior valor médio na segunda colheita.

Com colheita, na quarta geração, observase aumento no número de perfilhos basilares, independente do tratamento. Em situação relativamente semelhante, em termos de estrutura pós- colheita do capim-braquiária, diferenças nos valores médios do número de perfilhos, bem como nas taxas de aparecimento de perfilhos podem ser derivadas do resíduo da adubação da cultura agrícola, sendo responsável por acelerar os processos metabólicos, modificando a morfogênese da planta. Portes et al., (2000), observaram comportamento semelhante ao avaliar Urochloa brizantha cv. Marandú em consórcio com diferentes culturas, sendo os mesmos fatores relatados, responsáveis por reestabelecer às taxas de crescimento da gramínea.

Nota-se que houve diferença significativa $(P<0,05)$ entre os tratamentos para a produção de massa seca total na primeira colheita (momento da retirada das culturas agrícolas), tendo sido observados menores valores de massa seca total, assim como maiores para massa seca de colmo para o capimbraquiária cultivado em consórcio com milho (Tabela 5). Para a característica produção de lâminas foliares 0 capim-braquiária em consórcio com sorgo apresentou os maiores valores médios, já para produção de forragem morta, além do consórcio com o sorgo, o capimbraquiária em monocultivo apresentou os maiores valores. Na segunda colheita, o capim-braquiária consorciado ao sorgo e milho apresentou os maiores valores médios para as características produção de massa seca total, lâminas foliares e forragem morta $(P<0,05)$. Não houve diferenças significativas $(P>0,05)$ para produção de colmos.

Tabela 5. Produção de massa seca total, lâminas foliares, colmos e forragem morta do capim-braquiária consorciado e em monocultivo

\begin{tabular}{|c|c|c|c|c|}
\hline \multirow{2}{*}{ Variáveis } & \multicolumn{3}{|c|}{ Braquiária } & \multirow{2}{*}{$\mathrm{CV}(\%)$} \\
\hline & Monocultivo & Milho & Sorgo & \\
\hline \multicolumn{5}{|c|}{ Pré-colheita } \\
\hline MST (g) & $220,46 \mathrm{a}$ & $189,30 \mathrm{~b}$ & $227,35 \mathrm{a}$ & 14,55 \\
\hline $\operatorname{MSLF}(\mathrm{g})$ & $101,59 b$ & $98,10 \mathrm{~b}$ & $111,24 a$ & 18,16 \\
\hline $\operatorname{MSC}(\mathrm{g})$ & $86,13 a b$ & $100,54 a$ & $66,65 \mathrm{~b}$ & 13,46 \\
\hline MSFM (g) & $32,72 a$ & $7,55 \mathrm{~b}$ & $15,56 \mathrm{a}$ & 38,92 \\
\hline \multicolumn{5}{|c|}{ Pós-colheita } \\
\hline MST (g) & $45,56 \mathrm{~b}$ & $58,44 a$ & $72,16 a$ & 13,87 \\
\hline $\operatorname{MSLF}(\mathrm{g})$ & $9,06 \mathrm{~b}$ & $15,47 a$ & $12,96 \mathrm{a}$ & 20,23 \\
\hline MSC (g) & 31,03 & 27,36 & 29,36 & 29,76 \\
\hline MSFM (g) & $15,46 \mathrm{~b}$ & $15,60 \mathrm{~b}$ & $29,83 a$ & 18,40 \\
\hline
\end{tabular}

$\overline{C V}=$ Coeficiente de variação. Médias na mesma linha, seguidas por letras diferentes diferem ao nível de $5 \%$ de probabilidade pelo teste de Tukey. 
No intuito de elevar suas lâminas foliares em um plano mais alto do dossel em busca da luz, é comum observar aumentos principalmente nas taxas de alongamento de colmo (Casagrande et al., 2010; Cândido et al., 2005; Paula et al., 2012), não sendo diferente para o capim-braquiária (Tabela 2) consorciado com milho e sorgo. Com maiores taxas de alongamento de colmo no capim-braquiária consorciado com o milho, pode-se observar que esta apresentou maior altura ao final do ciclo da cultura do milho, uma vez que até a colheita da cultura não houve corte ou pastejo, de modo a controlar alongamento dos colmos.

Com maior altura e, ou, tempo de rebrotação, há aumento da senescência e morte de lâminas foliares (diminuição da duração de vida da folha) e colmos, incrementando a produção desse componente (Vilela et al., 2012; Sousa et al., 2012; Santos et al., 2009). Mesmo com menores taxa de senescência foliar na précolheita (Tabela 2), o monocultivo do capim-braquiária apresentou maiores valores para característica massa seca de forragem morta (Tabela 5). Este comportamento pode ser atribuído ao fato de que quando um dossel forrageiro de gramíneas ultrapassa seu IAF crítico (acima dos $95 \%$ de interceptação luminosa) há perdas excessivas por senescência e morte de órgãos e tecidos (Parsons e Penning, 1988). Devido à baixa competitividade por recursos tróficos, o capim-braquiária em monocultivo ultrapassou e permaneceu além deste ponto mais rápido e por período de tempo maior que plantas em sistema de integração, acarretando, desse modo, em maiores valores de massa seca de forragem morta. Ademais, o capim-braquiária em monocultivo, apresentou maior massa seca total, havendo desse modo maior massa disponível para processos de respiração e senescência.

Com relação à composição química do capimbraquiária, houve diferença significativa $(P<0,05)$ apenas para característica matéria mineral, não havendo desse modo, diferenças $(P>0,05)$ entre os sistemas de cultivo para teores de proteína bruta, fibra em detergente neutro e fibra em detergente ácido (Tabela 6).

Tabela 6. Teores de matéria mineral, proteína bruta, fibra em detergente neutro e ácido do capim-braquiária consorciado ou em monocultivo

\begin{tabular}{ccccc}
\hline \multirow{2}{*}{ Variáveis } & \multicolumn{3}{c}{ Braquiária } & \multirow{2}{*}{ CV $(\%)$} \\
\cline { 2 - 4 } & Monocultivo & Milho & Sorgo & 4,2 \\
MM $(\mathrm{g} / \mathrm{kg})$ & $84,3 \mathrm{a}$ & $47,4 \mathrm{c}$ & $72,7 \mathrm{~b}$ & 12,8 \\
PB $(\mathrm{g} / \mathrm{kg})$ & 106,3 & 97,6 & 119,4 & 13,5 \\
FDN $(\mathrm{g} / \mathrm{kg})$ & 587,9 & 592,7 & 514,1 & 14,3 \\
FDA $(\mathrm{g} / \mathrm{kg})$ & 244,8 & 229,4 & 256,9 & \\
\hline
\end{tabular}

Matéria mineral (MM); Proteína bruta (PB); Fibra em detergente neutro (FDN); Fibra em detergente ácido (FDA). Médias na mesma linha, seguidas por letras diferentes diferem ao nível de $5 \%$ de probabilidade pelo teste de Tukey.

Por terem sido colhidas em condições semelhantes (tempo de rebrotação), o capim-braquiária apresentou composição química semelhante, havendo diferença apenas para característica matéria mineral (Tabela 6). A composição morfológica apresenta forte correlação com composição química da forragem colhida, além de outros fatores bióticos e abióticos. Amplitude valores próximos para características produção de massa seca de lâminas, colmos e forragem morta (Tabela 5), provavelmente pode ter sido a causa da não diferença para as características proteína bruta, fibra em detergente neutro e fibra em detergente ácido.
A produção de forragem, características morfogênicas e estruturais do capim-braquiária são influenciadas pelo sistema de cultivo na integração agricultura e pecuária somente no período précolheita. $O$ consórcio de capim-braquiária com milho ou sorgo, não modifica sua composição química, nem prejudica seu estabelecimento e favorece aumento na produção de massa seca após retirada das culturas agrícolas. 


\section{REFERÊNCIAS BIBLIOGRÁFICAS}

Brambilla, J.A.; Lange, A.; Buchelt, A.C.; Massaroto, J.A. Produtividade de milho safrinha no sistema de integração lavoura-pecuária, na região de sorriso, Mato Grosso. Revista Brasileira de Milho e Sorgo, 2009, 8, 3, 263-274.

Cândido, M.J.D.; Gomide, C.A.M.; Alexandrino, E.; Gomide, J.A.; Pereira, W.E. Morfofisiologia do dossel de Panicum maximum cv Mombaça sob lotação intermitente com três períodos de descanso. Revista Brasileira de Zootecnia, 2005, 34, 2, 406-415.

Casagrande, D.R.; Ruggieri, A.C.; Janusckiewicz, E.R.; Gomide, J.A.; Reis, R.A.; Valente, A.L.S. Características morfogênicas e estruturais do capim-marandu manejado sob pastejo intermitente com diferentes ofertas de forragem. Revista Brasileira Zootecnia, 2010, 39, 10, 2108-2115.

Chapman, D.F.; Lemaire, G. Morphogenetic and structural determinants of plant regrowth after defoliation. In: International Grassland Congress, 17, Austrália, Proceedings, ed., 1993, 95-104.

Deregibus, V.A.; Sanchez, R.A.; Casal, J.J. Effects of light quality on tiller production in "Lolium spp". Plant Physiology, 1983, 72,900-902.

Detmann, E.; Souza, M.A.; Valadares Filho, S.C.; Queiroz, A.C.; Berchielli, T.T.; Saliba, E.O.S.; Cabral, L.S.; Pina, D.S.; Ladeira, M.M.; Azevedo, J.A.G. Métodos para análise de alimentos - INCT - Ciência Animal. Visconde do Rio Branco: Suprema, 2012, 214.

EMBRAPA, Centro Nacional de Pesquisa de Solos. Sistema Brasileiro de classificação de solos ( $3^{\mathrm{a}}$ edição). Brasilia: Embrapa Solos, 2013.

Leonel, F.P.; Pereira, J.C.; Costa, M.G.; Marco Júnior, P.; Lara, L.A.; Queiroz, A.C. Comportamento produtivo e características nutricionais do capim-braquiária cultivado em consórcio com milho. Revista Brasileira de Zootecnia, 2009, 38, 1,177-189.

Lopez, S.; France, J.; Gerrist, W.J.J.; Dhanos, M.S.; Humphriest, D.J.; Dijkstra, J.A generalized MichaelisMenten equation for the analysis of growth. Journal of Animal Science, 2000, 78, 7, 1816-1828.
Moraes, A.; Carvalho, P.C.F.; Anghinioni, I.; Lustosa, S.B.C.L.; Costa, A.S.E.V.G.; Kunrath, T.R. Integrated crop-livestock systems in the Brazilian subtropics. European Journal of Agronomy, 2014, 57, 4-9.

Nabinger, C.; Medeiros, R.B. Produção de sementes em Panicum maximum Jacq, In: SIMPÓSIO SOBRE MANEJO DA PASTAGEM, 12 Piracicaba, Anais, Piracicaba: ESALQ, 1995, 59-121.

Nascimento, W.G.; Prado, I.N.; Jobim, C.C.; Emile, J.C.; Surault, F.; Huyghe, C. Valor alimentício das silagens de milho e de sorgo e sua influência no desempenho de vacas leiteiras. Revista Brasileira de Zootecnia, 2008, $37,5,896-904$.

Parsons, A.J.; Penning, P.D. The effect of the duration of regrowth on photosynthesis, leaf death and the average rate of growth in a rotationally grazed sward. Grass and Forage Science, 1988, 43, 1, 15-27.

Paula, C.C.L.; Euclides, V.P.B.; Lempp, B. Barbosa, R.A.; Montagner, D.B.; Carloto, M.N. Acúmulo de forragem, características morfogênicas e estruturais do capim-marandú sob alturas de pastejo. Ciência Rural, 2012, 42, 11.

Portes, T.A.; Caravalho, S.I.C.; Oliveira, I.P.; Kluhcouski, J. Análise de crescimento de uma cultivar de braquiária em cultivo solteiro e consorciado com cereais. Pesquisa Agropecuária Brasileira, 2000, 35, 7, 1349-1358.

Santos, M.E.R.; Fonseca, D.M.; Euclides, V.P.B.; Nascimento, J.; Queiroz, A.C.; Ribeiro Júnior, J.I. Características estruturais e índice de tombamento de Brachiaria decumbens cv, Basilisk em pastagens diferidas. Revista Brasileira de Zootecnia, 2009, 38, 4, 626-634.

SAS Institute, SAS/STAT: user's Guide, Version 9.2, Cary: SAS Institute, 2009, 7869.

Sousa, B.M.L.; Santos, M.E.R.; Vilela, H.H.; Silveira, M.C.T.; Rocha, G.O.; Freitas, C.A.S.; Silva, N.A.M.; Nascimento Junior, D. Piata palisade grass deferred with two distinct initial heights: luminous environment and tillering dynamics. Revista Brasileira de Zootecnia, 2013, 42, 1, 36-43. 
Vilela, H.H.; Sousa, B.M.L.; Santos, M.E.R.; Santos,

A.L.; Assis, C.Z.; Rocha, G.O.; Faria, B.D.; Nascimento Júnior, D. Forage mass and structure of piata grass deferred at different heights and variable periods. Revista Brasileira Zootecnia, 2012, 41, 7, 1625-1631. 